\title{
A mechanistic approach to investigate drilling of UD-CFRP laminates with PCD drills
}

\author{
Y. Karpat ${ }^{\mathrm{a}, *}$, O. Bahtiyar ${ }^{\mathrm{b}}$, B. Değer ${ }^{\mathrm{b}}$, Bilgin Kaftanoğlu (1 ${ }^{\mathrm{c}}$ \\ ${ }^{a}$ Bilkent University, Department of Industrial Engineering, Bilkent, Ankara, Turkey \\ ${ }^{\mathrm{b}}$ Turkish Aerospace Industries (TAI), Kazan, Ankara, Turkey

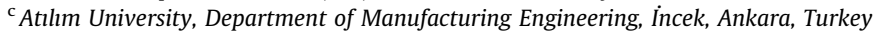

A R T I C LE I N F O

\section{Keywords:}

Machining

Drilling

Fiber reinforced plastic

\begin{abstract}
A B S T R A C T
Carbon fiber reinforced plastics (CFRPs) possess desirable material properties that satisfy the aerospace industry's high strength to weight ratio objective. Therefore, CFRPs are commonly used in structural parts, either alone or together with aluminum and titanium alloys. Drilling of CFRPs has been studied extensively in the literature in recent years, with special emphasis on process parameters and delamination. This study identifies mechanical properties of uni-directional CFRPs through drilling tests. Drilling of uni-directional CFRP plates with and without pilot holes has been performed, and cutting and edge force coefficients are identified. A polycrystalline diamond (PCD) drill was used in tests since this type of drill is commonly used in practice. Finally, validation tests on multi directional CFRP laminates have been performed and good results have been obtained.
\end{abstract}

(C) 2014 CIRP.

\section{Introduction}

In the new generation of aircrafts, the percentage of carbon fiber reinforced plastics (CFRP) has reached up to $40 \%$ due to their ability to resist corrosion and withstand high loads while reducing the weight of the structural parts. Drilling, the most common machining operation in aircraft manufacturing is the subject of this paper.

CFRPs are known to be difficult to machine due to the abrasive nature and low thermal conductivity. CFRP drilling has been the subject of many studies in the literature, most of which consider the influence of drilling conditions on delamination [1,2]. A "critical thrust force" concept (after which delamination starts) has been introduced by König et al. [3]. Many different mathematical models have been proposed to predict the critical thrust force as a function of tool geometry and FRP material properties [4,5]. It has been shown that feed and tool geometry are the two most important input parameters affecting the quality of drilled holes, and feed and drilling thrust force are closely related. It has been recommended to set feed low. The influence of drilling speed on the hole quality is shown to be minimal; therefore, high drilling speeds are recommended for better productivity [6]. Rapid tool wear is common while drilling CFRP laminates, which leads to increased drilling forces. Increased thrust forces result in delamination at the exit of the drilled holes. Low feed, which is recommended to decrease thrust forces at the hole exit, increases the total contact time between tool and CFRP and therefore results in faster tool wear [7]. In order to increase productivity, especially when drilling uni-directional CFRPs, diamond coated

\footnotetext{
* Corresponding author. Tel.: +90 3122902263.

E-mail address: ykarpat@bilkent.edu.tr (Y. Karpat).
}

tungsten carbide and polycrystalline diamond ( $\mathrm{PCD}$ ) drills have also been used. PCD tool material combines high abrasion resistance, thermal conductivity, hardness, and impact toughness, and it can also be used in drilling of metal composite stacks [8]. The cutting edge radius of PCD drills is sharper than it is on diamond coated carbide drills thanks to their small grain size, which is an important consideration for hole quality. In addition, they can be reconditioned when they are worn. However, there are only a limited number of studies on CFRP drilling with PCD drills in the literature.

It must be noted that the material properties and hence chip formation mechanism of metals and fiber reinforced plastics are different. CFRP material properties such as its thickness, carbon fiber diameter, type of resin, volumetric ratio of carbon fiber, elasticity modulus, strength, curing conditions, etc. are known to affect material properties and, in turn, its drilling characteristics. Therefore, drill geometries may be customized depending on the CFRP material and laminate properties. Modeling of CFRP drilling is therefore necessary to understand the mechanics of the process and to improve/optimize drill designs for better hole making performance [9].

This study conducts an experimental investigation of drilling CFRPs with PCD tools. The thrust force and torque measurements are used to identify cutting force and edge coefficients while drilling CFRPs. These identified cutting and edge coefficients are then validated with additional drilling experiments performed on single direction CFRP laminates.

\section{Experimental procedure}

A five-axis machining center was used in drilling experiments which were performed under wet conditions with emulsion type coolant. An aluminum backing plate with $8 \mathrm{~mm}$ diameter holes 
was placed under the CFRP laminate. The drilling forces and torque were measured by a Kistler 9123 rotating dynamometer and its charge amplifier. Drilling speed is carefully selected to obtain an acceptable level of cutting speed without exciting the dynamics of the rotational force dynamometer. Intermediate modulus UDCFRP laminates of $10 \mathrm{~mm}$ thickness are produced for drilling tests. UD-CFRP laminates have $0.14 \mathrm{~mm}$ ply thickness and they consist of 72 layers with equal fiber directions repeating in a sequence of $0 \%$ $45^{\circ} / 90^{\circ} / 135^{\circ}$ with two layers of $45^{\circ}$ and $135^{\circ}$ laminates on the top and bottom surfaces. The intermediate modulus carbon fiber reinforce epoxy resin unidirectional tape used in this study has 59\% fiber volume with $2690 \mathrm{MPa}$ tensile strength. The geometry of the double point angle PCD drill used in this study is shown in Fig. 1a and $b$. Many different PCD drill designs are available with varying cutting edge lengths and angles.

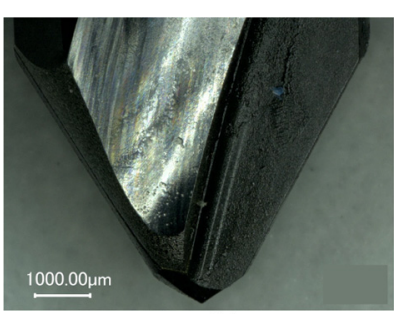

(a)

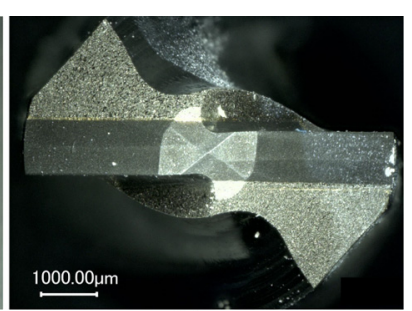

(b)
Fig. 1. Double tip point angle PCD drill geometry.

A generalized double point angle tool geometry is shown in Fig. 2. In this figure; $O^{\prime}-O$ represents the chisel edge region, $O A$ shows the primary drilling region, $A B$ shows the secondary drilling region and $B C$ shows the tertiary drilling region. The length and angle of the chisel edge are represented with $L$ and $\gamma$, respectively.

The tool tip angles corresponding to primary and secondary drilling regions are shown with $\alpha$ and $\beta$. The drill has zero helix angle and $120^{\circ}$ and $30^{\circ}$ tool tip angles. Table 1 summarizes tool geometry measurements. The tool tip measurements were performed using Keyence VHX 1000 digital microscope. Uncut chip thicknesses $t_{A B}$ and $t_{O A}$ are different due to double point angle design, and they can be calculated as a function of feed $(f)$ per edge.

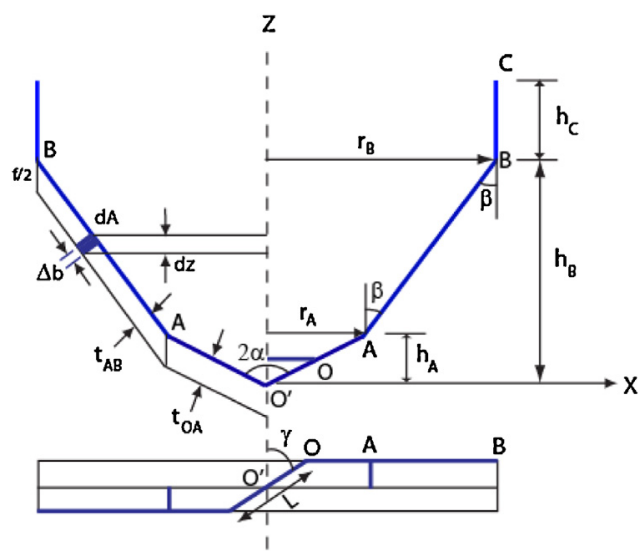

Fig. 2. Double tip point angle PCD drill geometry.

Table 1

Tool geometry measurements.

\begin{tabular}{llllllll}
\hline $\begin{array}{l}\text { Diameter } \\
\left(2 . \mathrm{r}_{\mathrm{B}}\right)(\mathrm{mm})\end{array}$ & $2 \alpha\left(^{\circ}\right)$ & $\beta\left(^{\circ}\right)$ & $L(\mu \mathrm{m})$ & $\gamma\left(^{\circ}\right)$ & $r_{\mathrm{A}}(\mathrm{mm})$ & $O A(\mathrm{~mm})$ & $A B(\mathrm{~mm})$ \\
\hline 6.4 & 120 & 30 & 1250 & 37 & 0.82 & 0.46 & 4.4 \\
\hline
\end{tabular}

\section{Thrust force and torque characteristics of drilling with double point angle PCD drills}

Important information about the influence of tool geometry and drilling conditions can be deduced from force and torque measurements during drilling. Fig. 3 illustrates a drilling cycle with the double point angle PCD drill used in this study, and phases I-VII are identified on the figure. The point (I) corresponds to the chisel edge of the drill entering the material. The point (II) indicates the situation when the primary cutting edge $(O A)$ enters the hole. In this region, while thrust force increases rapidly, the increase in torque is small. When the secondary drilling zone enters the hole $(A B)$, the rate of increase in thrust force is lower due to chip thinning as a result of lower drill angle $(\beta)$. Peak thrust force (III) is reached at the end of the secondary drilling zone, and it stays almost steady until the chisel edge of the drill reaches the bottom of the laminate (IV). The region $B C$ does not carry any thrust force, but the torque reaches its peak value here. Thrust force decreases rapidly with a similar rate observed at the hole entry as soon as the chisel edge (IV-V) and primary drilling edge $(\mathrm{V}-\mathrm{VI})$ leave the cut. The torque stays almost the same between IV and VI since the secondary and tertiary cutting edges are still in contact with the material. The thrust force and torque decrease continuously between VI and VII until the drill completely leaves the cut.

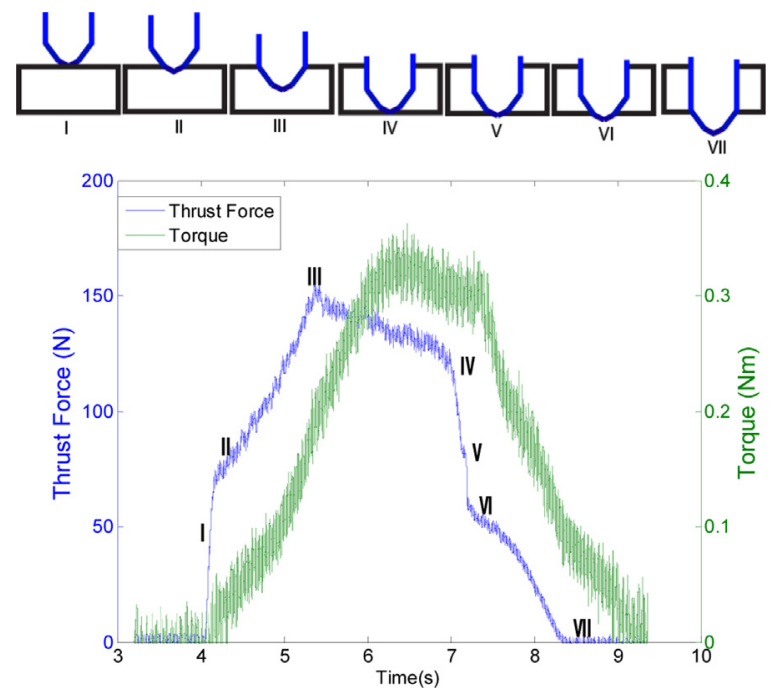

Fig. 3. A typical thrust force and torque measurement during drilling with double point angle PCD tools at $5000 \mathrm{rpm}$ and $0.04 \mathrm{~mm} / \mathrm{rev}$ feed (data low pass filtered at $100 \mathrm{~Hz}$ ).

\section{Modeling of drilling forces and torques}

The total thrust force $\left(F_{z}\right)$ and torque acting on the tool can be represented with Eq. (1). The first term $\left(F_{z-c h}\right)$ represents the influence of the chisel edge, the second term $\left(F_{z-O A}\right)$ represents the influence on the primary drilling edge, and the last term $\left(F_{z-A B}\right)$ represents the influence of the secondary drilling edge. The effect of the $B C$ region on the thrust forces is neglected. A similar equation can also be written for total drilling torque $(T)$ also shown in Eq. (1).

$\sum F_{z}=F_{z_{-} c h}+F_{z_{-} O A}+F_{z-A B}$
$\sum T=T_{O A}+T_{A B}+T_{B C}$

A mechanistic force modeling approach has been used to model drilling thrust forces and torques where machining forces are related to the uncut chip area [10,11]. Average force and edge coefficients represent the influences of drills' cutting edge and material properties on the forces. Eq. (2) represents the mechanistic force modeling (thrust and cutting force per edge) adapted to drilling with a double point angle tool. The subscript $p$ represents 
primary $(O A)$ and subscript $s$ represents secondary $(A B)$ drilling regions. The variables in Eq. (2) are shown above in Fig. 2. The thrust and cutting forces can be calculated for known values of average force and edge coefficients.

$$
\begin{aligned}
& F_{z p}=O A\left(\bar{K}_{z p} \frac{f}{2} \sin \alpha+\bar{K}_{z e p}\right), \quad T_{O A}=F_{c p} \cdot \bar{r}_{O A}=O A\left(\bar{K}_{c p} \frac{f}{2} \sin \alpha+\bar{K}_{c e p}\right) \\
& F_{z s}=A B\left(\bar{K}_{z s} \frac{f}{2} \sin \beta+\bar{K}_{z e s}\right), \quad T_{A B}=F_{c s} \cdot \bar{r}_{A B}=A B\left(\bar{K}_{c s} \frac{f}{2} \sin \beta+\bar{K}_{c e s}\right) \\
& T_{B C}=F_{B C} \cdot r_{B C}=B C(\bar{K} p)
\end{aligned}
$$

Drilling tests can be used to calculate the average values of thrust and cutting force $\left(K_{z p}, K_{c p}, K_{z s}, K_{c s}\right)$ and edge $\left(K_{z e p}, K_{c e p}, K_{z e s}\right.$, $K_{\text {ces }} K_{p}$ ) coefficients in reverse fashion. Characteristic thrust forces and torques at drilling points (as shown I to IV in Fig. 3) are identified from the measurements and shown in Fig. 4.

The primary edge thrust force is calculated by subtracting the chisel edge force from the thrust force measurements $\left(F z p=F_{\mathrm{II}}-F_{\mathrm{I}}\right.$ as shown in Figs. 3 and 4). Similarly, the secondary edge drilling thrust force is calculated by subtracting the primary edge force from the peak force $\left(F z s=F_{\text {III }}-F_{\text {II }}\right)$. A linear fit has been obtained for both thrust load and torque at primary, secondary and tertirary drilling regions as shown in Fig. 4. The chisel edge torque is neglected since it is very low. Table 2 summarizes the cutting and edge force coefficients obtained from thrust force and torque measurements. A linear curve fitting approach is also used to represent the influence of chisel edge $\left(F_{\mathrm{I}}\right)$ on the thrust force as a function of feed [10] which is also shown in Table 2.

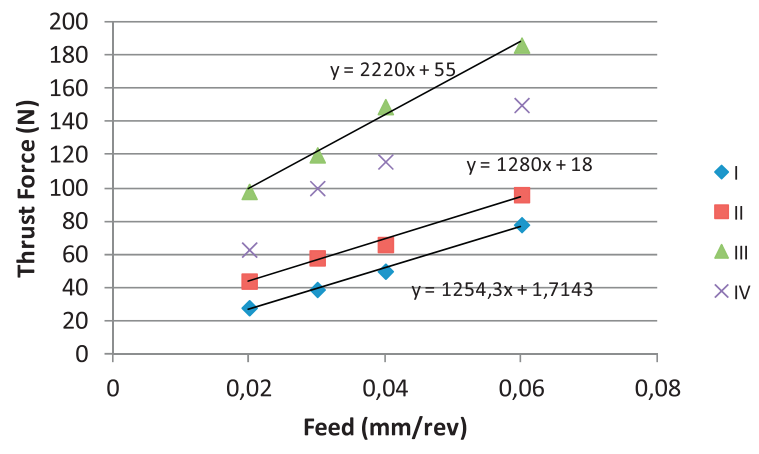

(a)

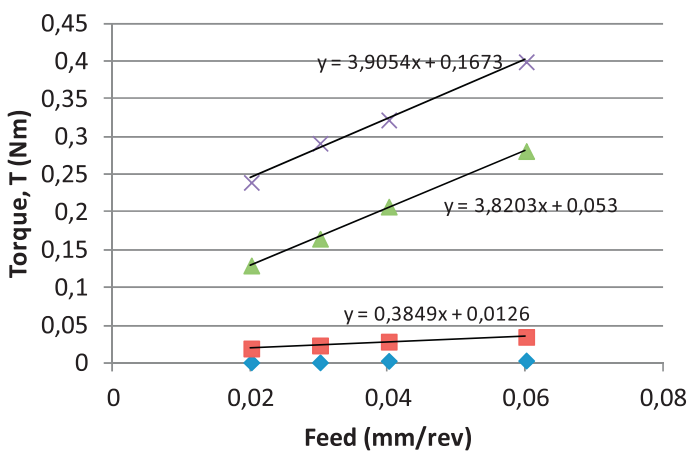

(b)

Fig. 4. (a) Thrust force and (b) torque measurements with linear fit equations.

Table 2

Identified average cutting and edge coefficients.

\begin{tabular}{lllll}
\hline \multicolumn{5}{c}{ Chisel edge force $F_{z_{c} c h}=1254 \mathrm{f}+1.71(\mathrm{~N})$} \\
\hline$K_{z p}\left(\mathrm{~N} / \mathrm{mm}^{2}\right)$ & $K_{\text {zep }}(\mathrm{N} / \mathrm{mm})$ & $K_{\text {zs }}\left(\mathrm{N} / \mathrm{mm}^{2}\right)$ & \multicolumn{2}{l}{$K_{\text {zes }}(\mathrm{N} / \mathrm{mm})$} \\
67 & 18 & 427 & \multicolumn{1}{c}{4.2} & \\
\hline$K_{\text {cp }}\left(\mathrm{N} / \mathrm{mm}^{2}\right)$ & $K_{\text {cep }}(\mathrm{N} / \mathrm{mm})$ & $K_{\text {cs }}\left(\mathrm{N} / \mathrm{mm}^{2}\right)$ & $K_{\text {ces }}(\mathrm{N} / \mathrm{mm})$ & $K_{p}(\mathrm{~N} / \mathrm{mm})$ \\
\hline 1317 & 22 & 810 & 2.38 & 7 \\
\hline
\end{tabular}

The edge force coefficients on the primary drilling region $\left(K_{z e p}\right.$ and $K_{\text {cep }}$ ) are quite large. This is expected since effective drilling cannot be performed in this region because of its closeness to drills' center. Force coefficient for torque $\left(K_{c s}\right)$ is larger than that of thrust force $\left(K_{z s}\right)$ for the secondary drilling edge. This is also expected, since most of the torque is carried on the secondary drilling edge. The edge coefficient on the tertiary zone $K_{p}$ is larger than that of secondary drilling edge coefficient $\left(K_{\text {ces }}\right)$ indicating a possible plowing action, which may help improve both the quality of the hole surface and the stability of the process. Average cutting and edge coefficients can be used to calculate drilling thrust forces and torques. A simple computer code is developed to calculate drilling time based on drill geometry and feed. Fig. 5 shows the predicted drilling thrust force and torques based on calculated cutting and edge force coefficients. The influence of the laminate's decreasing stiffness as the number of laminates decreases toward the end of the process is neglected. The peak force and peak torque are predicted as $170 \mathrm{~N}$ and $0.38 \mathrm{Nm}$, respectively. These are in agreement with the values presented in Fig. 4(a) and (b).

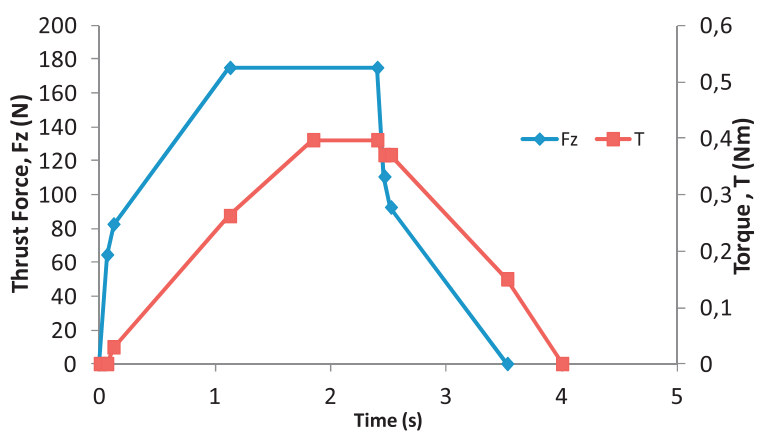

Fig. 5. Drilling thrust force and torque predictions at $5000 \mathrm{rpm}$ and $50 \mu \mathrm{m} / \mathrm{rev}$ feed.

\section{Cutting force coefficients as a function of fiber directions}

In order to observe the influence of fiber cutting angle during the drilling process, additional drilling tests are performed on a single direction UD-CFRP laminate. The definition of fiber cutting angle $(\theta)$ and the variation of fiber cutting angle during drilling cycle as a function drill's rotation are shown in Fig. 6.

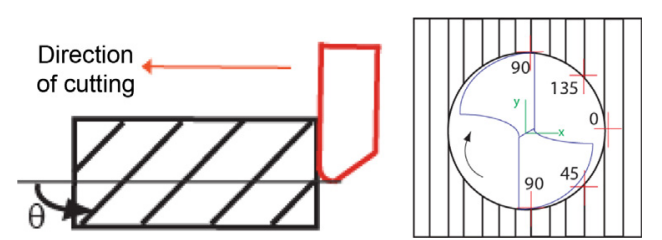

Fig. 6. Definition of fiber cutting angle, and variation of fiber cutting angle during one rotation of the drill.

The corresponding drilling thrust force and torque measurements are shown in Fig. 7. The variation of thrust force and torque measurements have been enlarged in the same figure. The average thrust force and torque are in good agreement with the predictions for multi direction laminate shown in Fig. 5. Experimenting on single direction CFRP laminates allow for obtaining cutting force coefficients as a function of fiber cutting angle $[12,13]$. The same approach is used here to represent the relationship between the fiber cutting angle and force coefficients. Additional drilling experiments are performed on pilot holes of $2.48 \mathrm{~mm}$ diameter where the influences of chisel and primary edges are removed from thrust force and measurements. High feed drilling tests were also performed where the largest feed of $0.15 \mathrm{~mm} / \mathrm{rev}$ was used which is larger than the ply thickness $(0.13 \mathrm{~mm})$ of the laminate. Average thrust force and 


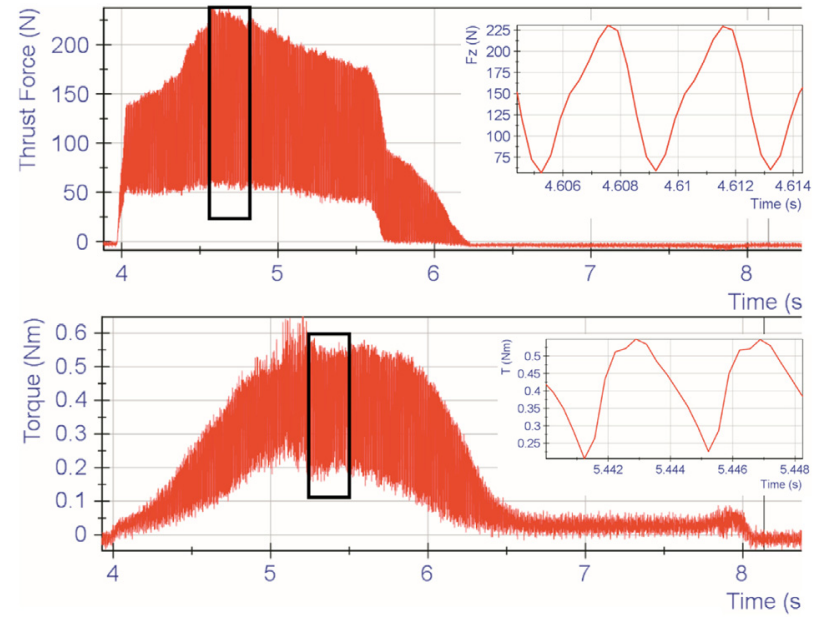

Fig. 7. Drilling of single direction CFRP laminate at $7500 \mathrm{rpm}$ and $50 \mu \mathrm{m} / \mathrm{rev}$ feed and variation of thrust forces and torques as a function of drill rotation.

torque measurements obtained on a pilot hole are given in Fig. 8 with linear fit equations.

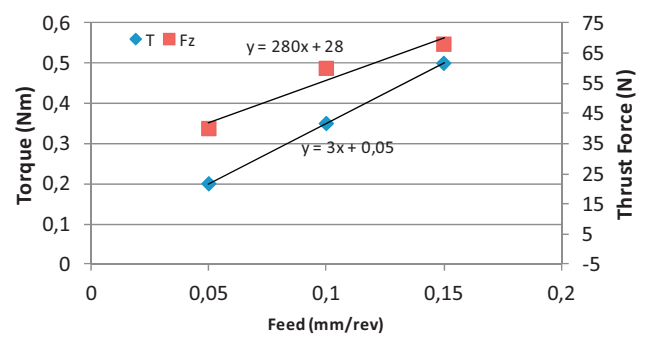

Fig. 8. Average peak thrust force and torque measurements as a function of feed while drilling with pilot hole of $2.48 \mathrm{~mm}$ diameter. Force and edge coefficients for the secondary drilling edge can be calculated as a function of fiber cutting angle as in Eq. (3).

$K_{c s}=689+345 \cdot \sin (2 \theta+180) \mathrm{N} / \mathrm{mm}^{2}, K_{\text {ces }}=2.88 \mathrm{~N} / \mathrm{mm}$

$K_{z s}=143+72 . \sin (2 \theta+180) \mathrm{N} / \mathrm{mm}^{2}, K_{z e s}=3.58 \mathrm{~N} / \mathrm{mm}$

The average values of the sine wave is calculated from slope and intercept values given in Fig. 8 using Eq. (2). The amplitude of the sine wave is calculated from single direction laminate force fluctuations as shown in Fig. 7. Fig. 9(a) shows the variation of $K_{c s}$ as a function of fiber cutting angle. There is almost a three times

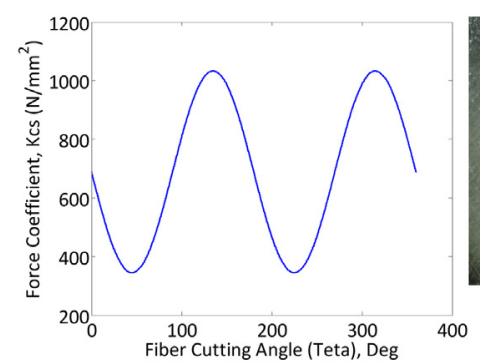

(a)

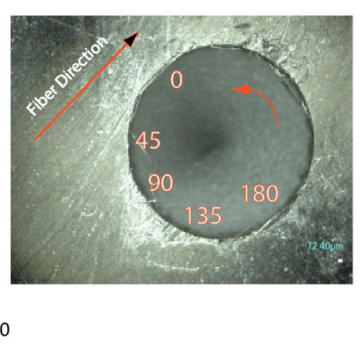

(b)
Fig. 9. (a) Cutting force coefficient as a function of fiber cutting angle in the secondary drilling region; (b) hole exit quality as a function of fiber cutting angle at $5000 \mathrm{rpm}$ and $20 \mu \mathrm{m} / \mathrm{rev}$ feed. difference in force coefficients between $45^{\circ}$ and $135^{\circ}$ fiber cutting angles. The adverse effect of high levels of force coefficients (from $90^{\circ}$ to $135^{\circ}$ fiber cutting angle) on the hole exit quality is shown in Fig. 9(b). While the secondary drilling edge cutting $\left(K_{c s}\right)$ and edge force coefficients $\left(K_{c e s}, K_{z e s}\right)$ are in close agreements with those listed in Table 2, cutting force coefficient corresponding to thrust force $K_{z s}$ is calculated to be lower. Thrust force measurements in Fig. 8 reveal that rate of increase in thrust force decrease with increasing feed. This may be explained with the brittle fracturing of the fibers as a result of large thrust forces.

\section{Conclusions}

A mechanistic model for drilling of multidirectional CFRP laminates using double point angle PCD drills is proposed. Cutting and edge force coefficients are calculated based on thrust force and torque measurements. The variation of cutting force coefficients as a function of fiber cutting angle is also calculated for the secondary drilling region. It allows calculation of thrust forces and torques according to laminate configuration. The proposed model enables investigating the influence of drill geometry and drilling parameters on process outputs such as thrust forces and torques at the hole exit. This model, combined with experimental delamination analysis, can be used to optimize drilling conditions and drill geometry. Chisel edge length and angle, primary and secondary edge lengths and angles can be considered as drill geometry parameters for the PCD drill used in this study.

\section{Acknowledgement}

The authors would like to acknowledge financial support from the Scientific and Technological Research Council of Turkey (Tubitak-Teydeb 3090513).

\section{References}

[1] Teti R (2002) Machining of composite materials. CIRP Ann Manufact Technol 51:611-634.

[2] Dandekar CR, Shin YC (2012) Modeling of machining of composite materials: a review. Int J Mach Tool Manufact 57:102-121.

[3] König W, Wulf Ch, Graß PH (1985) Willerscheid machining of fibre reinforced plastics. CIRP Ann Manufact Technol 34(2):537-548.

[4] Hocheng H, Tsao CC (2006) Effects of special drill bits on drilling-induced delamination of composite materials. Int J Mach Tool Manufact 46(1213):1403-1416.

[5] Lachaud F, Piquet R, Collombet F, Surcin L (2001) Drilling of composite structures. Compos Struct 52:511-516.

[6] Rawat S, Attia H (2009) Characterization of the dry high speed drilling process of woven composites using machinability maps approach. CIRP Ann Manufact Technol 58:105-108.

[7] Karpat Y, Değer B, Bahtiyar O (2012) Drilling thick fabric woven CFRP laminates with double point angle drills. J Mater Process Technol 212(10):21172127.

[8] Park K, Beal A, Kim D, Kwon P, Lantrip J (2011) Tool wear in drilling of composite/titanium stacks using carbide and polycrystalline diamond tools. Wear 271(11-12):2826-2835.

[9] Schulze V, Becke C, Pabst R (2011) Specific machining forces and resultant force vectors for machining of reinforced plastics. CIRP Ann Manufact Technol 60(1):69-72.

[10] Pirtini M, Lazoglu I (2005) Forces and hole quality in drilling. Int J Mach Tool Manufact 45(11):1271-1281.

[11] Langella A, Nele L, Maio A (2005) A torque and thrust force prediction model for drilling of composite materials. Compos A: Appl Sci Manufact 36:83-93.

[12] Karpat Y, Değer B, Bahtiyar O (2012) Mechanistic force modeling for milling of unidirectional carbon fiber reinforced polymer laminates. Int J Mach Tool Manufact 56:79-93.

[13] Karpat Y, Polat N (2013) Mechanistic force modeling for milling of carbon fiber reinforced polymers with double helix tools. CIRP Ann Manufact Technol 62:95-98 